\title{
Estimation of $\mathrm{NH}_{3}-\mathrm{N}$ Pollution Load and Analysis of the Spatial and Temporal Characteristics in Ningxia, China, The Yellow River
}

\author{
Sun Zhanchao, Feng Jing, Qian Hui \\ College of Environmental Science and Engineering, Chang'an University, Xi'an, China
}

Email address:

631531577@qq.com (Sun Zhanchao), 1277322080@qq.com (Feng Jing), 55480981@qq.com (Qian Hui)

\section{To cite this article:}

Sun Zhanchao, Feng Jing, Qian Hui. Estimation of $\mathrm{NH}_{3}-\mathrm{N}$ Pollution Load and Analysis of the Spatial and Temporal Characteristics in Ningxia, China, The Yellow River. International Journal of Environmental Monitoring and Analysis. Vol. 3, No. 5, 2015, pp. $341-346$.

doi: 10.11648/j.ijema.20150305.25

\begin{abstract}
In this paper, a new method of load estimation is used to estimate the pollution load of the three sections of Ningxia, China, the Yellow River section. The characteristic load method is used to analyze the $\mathrm{NH}_{3}-\mathrm{N}$ pollution load. According to the estimation results of pollutant load, we find the space-time characteristics of $\mathrm{NH}_{3}-\mathrm{N}$ pollution. We hope that it can provide theoretical basis and help for the comprehensive management of pollution in the Yellow River in Ningxia province, China.
\end{abstract}

Keywords: $\mathrm{NH}_{3}-\mathrm{N}$ Pollution, Non-point Source Pollution, Characteristic Load Method, Time and Space Characteristics

\section{Introduction}

Water pollution generally includes point source pollution and non-point source pollution. Point source pollution refers to the pollution sources with fixed point of discharge, which refers to the industrial wastewater and municipal sewage. Non point source pollution is the soil nitrogen, phosphorus, pesticides and other organic or inorganic pollutants, atmospheric dry deposition, urban and road pollutants, in the process of precipitation through surface runoff and underground seepage, into the surface and underground water, pollution of water [1].

Different from point source pollution, non point source pollution has the characteristics of dispersion, concealment, random, latent, cumulative and fuzzy. At present point source pollution has been effectively control and management, but the non point source pollution due to its characteristics is not easy to monitor, it is difficult to quantify, research and control of the difficulty, has become the main source of water pollution [2].

Since 2000, with the introduction of non point source pollution model, especially the mechanism model, China's non point source pollution research has begun to develop rapidly [3]. At present, there are export coefficient method [4], rainfall deduction method [5], runoff division method [6], correlation method of water quality and quantity [7], etc. These methods can estimate the load of non-point source pollution in the river basin, but it needs many reasons, such as many field materials, high cost and many parameters, which makes it difficult to estimate the non-point source pollution load. In this paper, we use the characteristic load method [8] to estimate the time and space characteristics of $\mathrm{NH}_{3}-\mathrm{N}$ pollutant load of Ningxia, China, the Yellow River section, which was proposed by Zhu Lei and Li Huaien.

\section{Basic Situation of Research Area}

Ningxia Hui Autonomous Region is one of the five Chinese ethnic minority areas, located in Northwest China Eastern, in the upper and middle reaches of the Yellow River Basin. Its southwest and Southeast connected Gansu, east connected Shaanxi, north connected Inner Mongolia. And its geographical coordinates is east longitude $104^{\circ} 17^{\prime}---109^{\circ} 39^{\prime}$, north latitude $35^{\circ} 14^{\prime}---39^{\circ} 23^{\prime}$. Its territory is long, north-south distance of about $465 \mathrm{~km}$ and east-west distance of about $45250 \mathrm{~km}$. Its total area is $66400 \mathrm{~km}^{2}$. Ningxia is located in the upper and middle reaches of the Yellow River, most of its areas belong to the Yellow River Basin.

The Yellow River is the main surface water of Ningxia, China. It flows from the nanchangtan of Zhongwei city, and the outflow from the first ridge North mahuanggou in 
Shizuishan city. Through the middle of the Wei Ning plain and the Yinchuan plain. Its length is 397 kilometers, accounting for $7.2 \%$ of the total length of the Yellow River. The Yellow River is the main water source of Ningxia agricultural, industrial and drinking water, while is the main channel of the Ningxia living and industrial waste water [9]. The Yellow River is the most important crossing river. According to the "environmental quality standard for surface water" (GB3838-2002), the Yellow River's entry section of Ningxia which named xiaheyan annual water quality as class category II, the water quality is better. But with the enterprise sewage discharge and urbanization process speeding up, in the Yellow River's exit section in Ningxia where named Mahuanggou, the annual water quality category as III class.

\section{Estimation Method and Calculation Process}

Because it is impossible to carry out the continuous monitoring of non-point source pollution, we need to use the appropriate method to estimate the non point source pollution load based on limited hydrological data.

\subsection{Main Idea}

This paper mainly uses the characteristic load method, which is a new method to estimate the annual pollution load of pollutants according to the characteristics of point source pollution and non-point source pollution. It is first proposed by Zhu Lei, Li Huaien, et al. The main idea is:

1) In a given year, the urban population has not changed significantly, and the emissions of pollutants in urban life are relatively stable, while the emissions of industrial waste water during the year don't change.

2) The total pollution load of the river basin can be obtained by calculation.

3) Non point source pollution load estimation can be obtained indirectly through total pollution load minus the point source pollution load.

\subsection{Main Formula}

The main reason of non-point source pollution is caused by rainfall runoff. In drought period, there is no rainfall in the basin basically. So the resulting pollutant load is mainly point source pollution load. So we can get the following formula:

$$
\begin{aligned}
& Y_{p}=\min \left(c_{i} \cdot w_{i}\right) \\
& Y_{t}=c_{i} \cdot w_{i} \\
& Y_{n p}=Y_{t}-Y_{p} \\
& N_{p}=12 \min \left(c_{i} \cdot w_{i}\right) \\
& N_{t}=\sum_{i=1}^{12} c_{i} \cdot w_{i} \\
& N_{n p}=N_{t}-N_{p}
\end{aligned}
$$

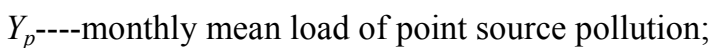

$Y_{t^{----} \text {monthly total load; }}$

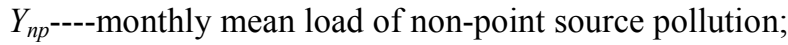

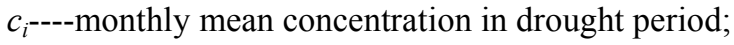

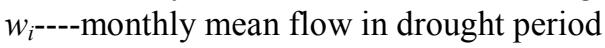

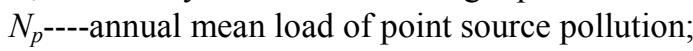

$N_{t^{-}-\text {--annual total load; }}$

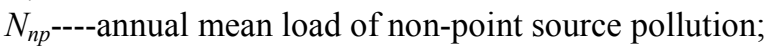
$i$----mouth, $(i=1,2,3, \ldots \ldots, 12)$.

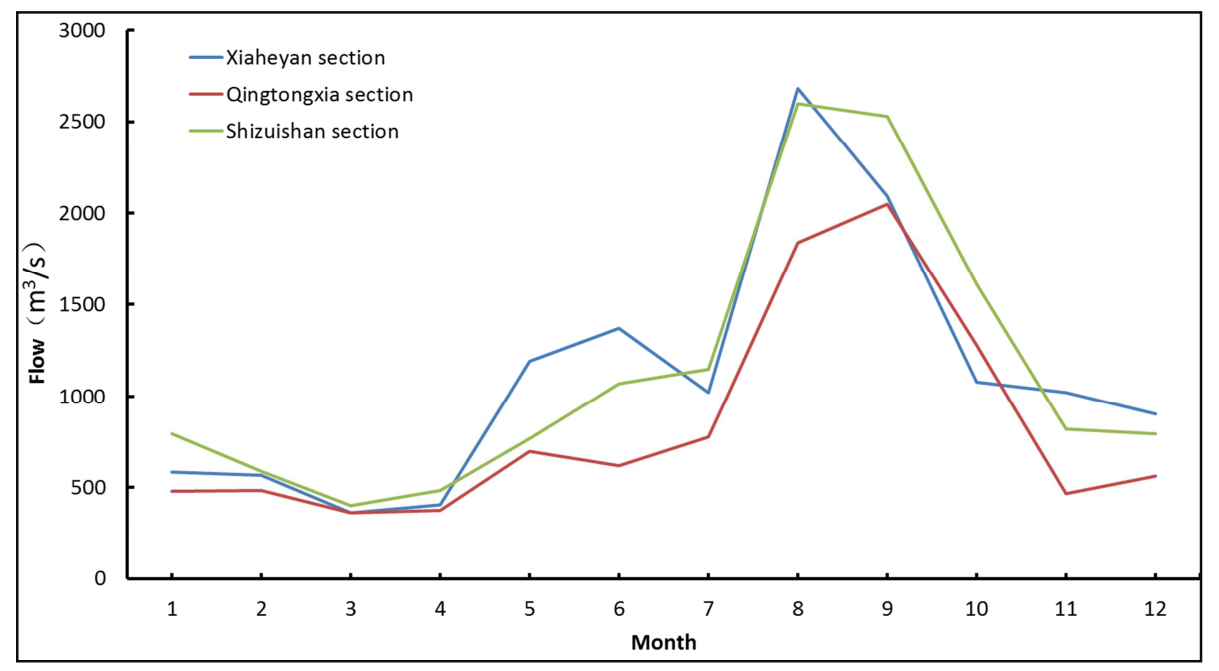

Figure 1. Flow of the three charateristic cross-sections.

\section{Estimation Results of Pollutant Load}

We select the upstream, middle and lower reaches of the
Yellow River section in Ningxia, China, as research object. At the same time, we choose three sections as our charateristic cross-sections. One of them is xiaheyan section located in the upstream. One of them is qingtongxia section located in the 
middle reach. One of them is shizuishan section located in the lower reach. And the $\mathrm{NH}_{3}-\mathrm{N}$ is selected as the water quality parameter. We estimate the point source pollution load and the non-point source pollution load of the three charateristic cross-sections in the selected year (2012). According to the characteristics of rainfall runoff, water period division are as follows: The wet period was June---September; the flat period is April, May, October and November; the drought period is January---March and December.

The Figure1 shows the flow of the three charateristic cross-sections in the selected year.

Just like Figure 1 shows: the tendency of changes in flow over time not too big difference. From January to March, the flow of three charateristic cross-sections decreases. After the minimum appears in March, the flow increases. In June or July, the flow of three charateristic cross-sections has a slight decline. After that, the flow continue to increase until the peak in August or September. Then the flow of three charateristic cross-sections decreases.

The flow minimum of xiaheyan section is $361 \mathrm{~m} 3 / \mathrm{s}$ where it appeares in March. And its peak is $2680 \mathrm{~m} 3 / \mathrm{s}$ where it appears in August. The flow minimum of qingtongxia section is $362 \mathrm{~m} 3 / \mathrm{s}$ where it appeares in March.And its peak is $2050 \mathrm{~m} 3 / \mathrm{s}$ where it appears in September. The flow minimum of shizuishan section is $400 \mathrm{~m} 3 / \mathrm{s}$ where it appears in March. And its peak is $2600 \mathrm{~m} 3 / \mathrm{s}$ where it appears in August.

According to the formula of formula 1 to 6 , and the known $\mathrm{NH}_{3}-\mathrm{N}$ pollutant data of three charateristic cross-sections. We use the characteristic load method to estimate the pollution load of the three sections of Ningxia the Yellow River section. The estimation results are indicated in Figure 2 to 4 and table 1 .

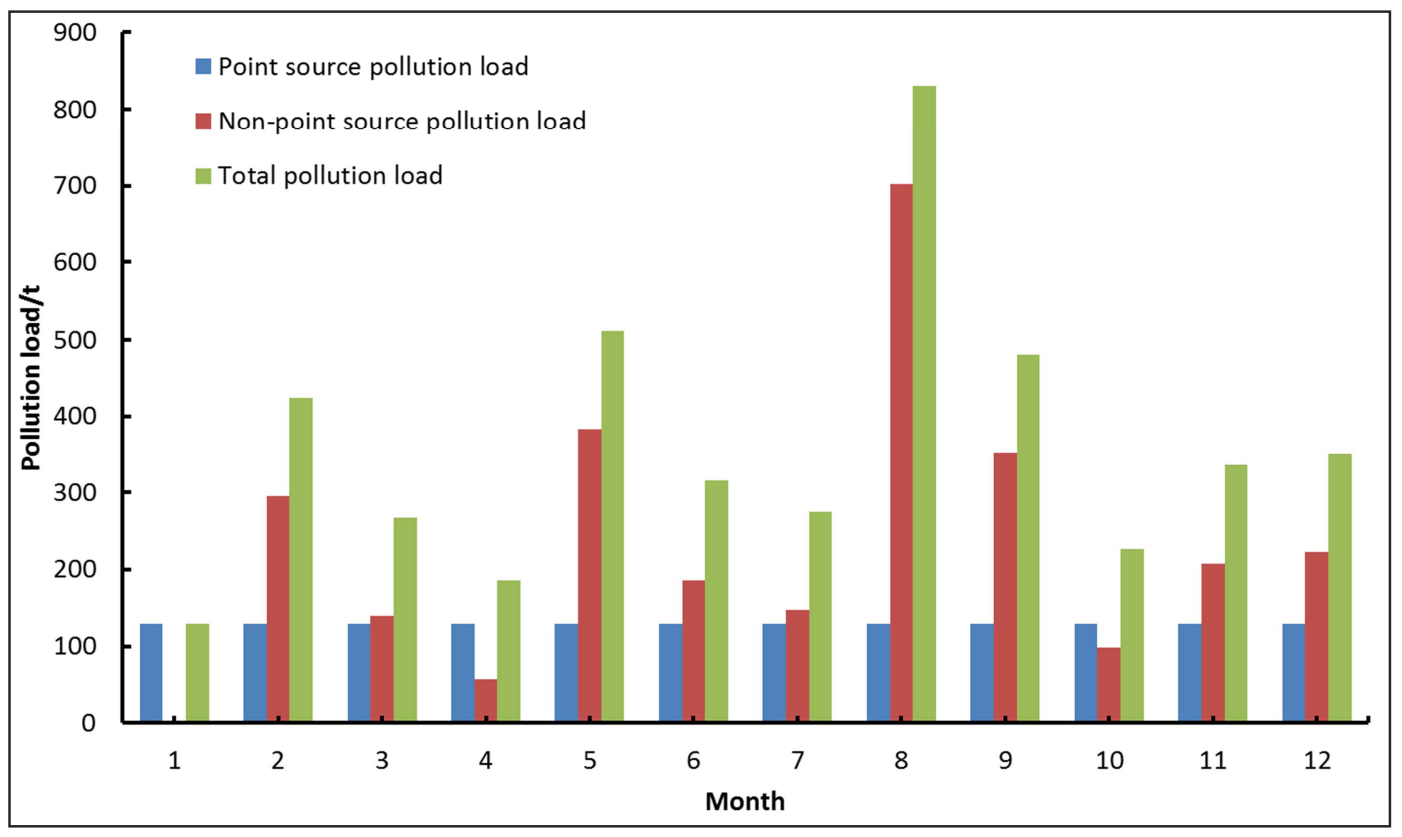

Figure 2. $\mathrm{NH}_{3}-\mathrm{N}$ pollutant load of xiaheyan section.

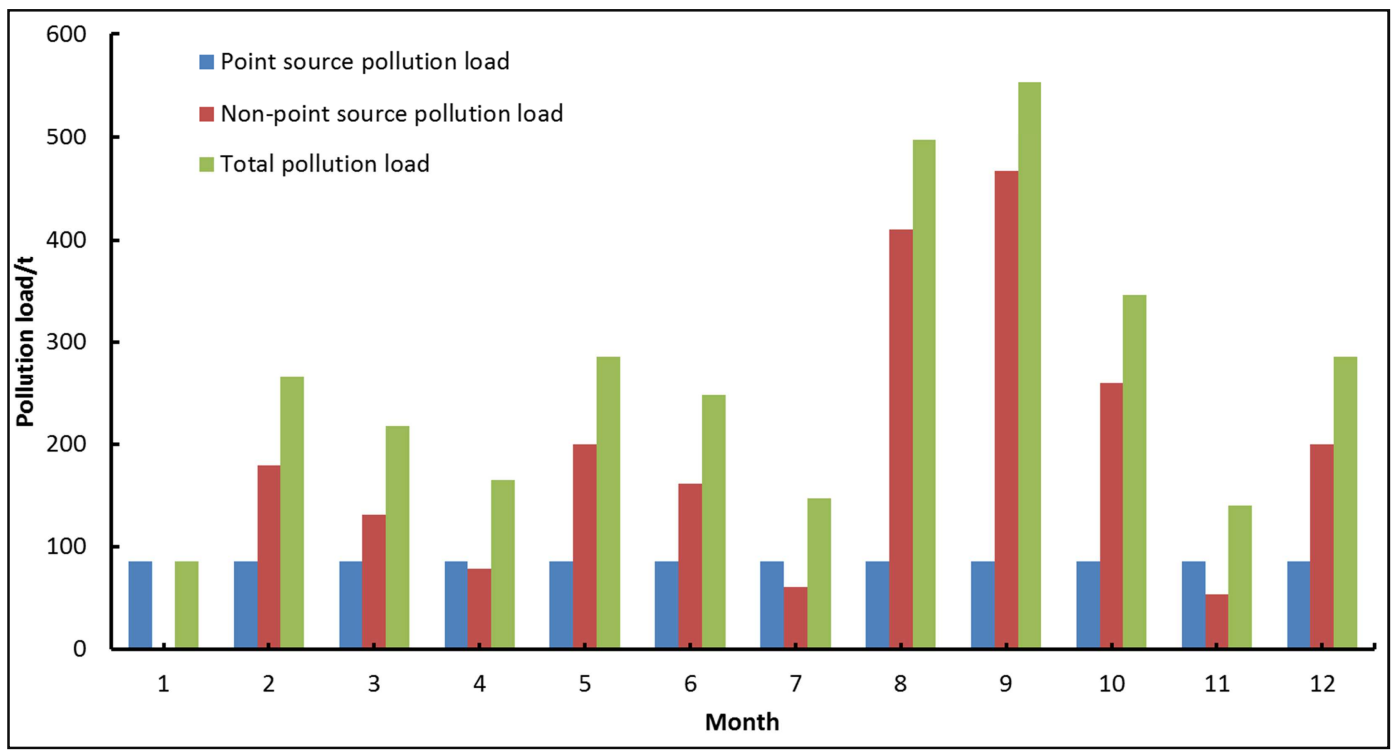

Figure 3. $\mathrm{NH}_{3}-\mathrm{N}$ pollutant load of qingtongxia section. 


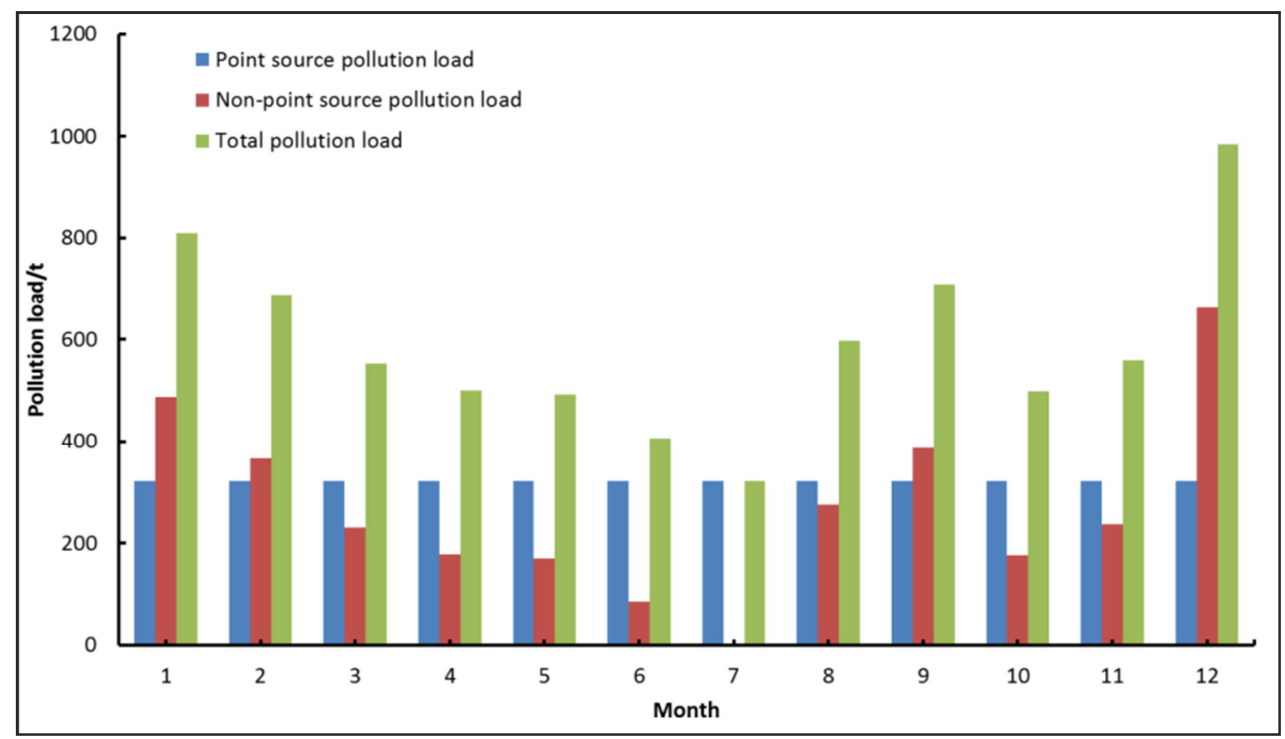

Figure 4. $\mathrm{NH}_{3}-\mathrm{N}$ pollutant load of shizuishan section.

Table 1. Annual average pollutant discharge of three section.

\begin{tabular}{llll}
\hline Section & Xiaheyan & Qingtongxia & Shizuishan \\
\hline $\begin{array}{l}\text { Point source pollution load/t } \\
\left(N_{P}\right)\end{array}$ & 1544.4 & 1034.64 & 3864 \\
$\begin{array}{l}\text { Non-point source pollution } \\
\text { load/t }\left(N_{n p}\right)\end{array}$ & 2789.91 & 2203.93 & 3254.79 \\
$\begin{array}{l}\text { Tatol point source pollution } \\
\text { load/t }\left(N_{t}\right)\end{array}$ & 4334.31 & 3238.57 & 7118.79 \\
$\begin{array}{l}\text { The proportion of point } \\
\text { source pollution load }\end{array}$ & 0.35632 & 0.319474 & 0.542789 \\
$\begin{array}{l}\text { The proportion of non-point } \\
\text { source pollution load }\end{array}$ & 0.64368 & 0.680526 & 0.457211 \\
\hline
\end{tabular}

\section{The Space-Time Characteristics of $\mathrm{NH}_{3}$-N Pollution}

Based on the field survey and relevant information and the estimation results of pollutant load,we try to analyze the temporal and spatial characteristics of $\mathrm{NH}_{3}-\mathrm{N}$ pollution, what can provide basic data and suggestions for better governance of the Yellow River.

\subsection{The Spatial Characteristics of $\mathrm{NH}_{3}-\mathrm{N}$ Pollution}

1). According to the estimation results, the $\mathrm{NH}_{3}-\mathrm{N}$ pollution load value of the three sections shows the following spatial rule: Shizuishan section $>$ Xiaheyan section $>$ Qingtongxia section.

According to the figure 5 and figure 6 , we find that the most main sewage points and drainage ditches are located in the basin above Shizuishan section. This leads to the $\mathrm{NH}_{3}-\mathrm{N}$ pollution load of Shizuishan section to be far greater than the other two sections. The $\mathrm{NH}_{3}-\mathrm{N}$ pollution load value of Qingtongxia section is lower than that of Xiaheyan section.According to the field investigation and lookup data; we find that there is a large reservoir, which named Qingtongxia reservoir, not far away from Qingtongxia section. When the Yellow River into the Qingtongxia reservoir, considering adsorption and dilution of pollutants, resulting in reduction of $\mathrm{NH}_{3}-\mathrm{N}$ concentration of pollutants. That leads to the $\mathrm{NH}_{3}-\mathrm{N}$ pollution load value of Qingtongxia section is lower than that of Xiaheyan section.

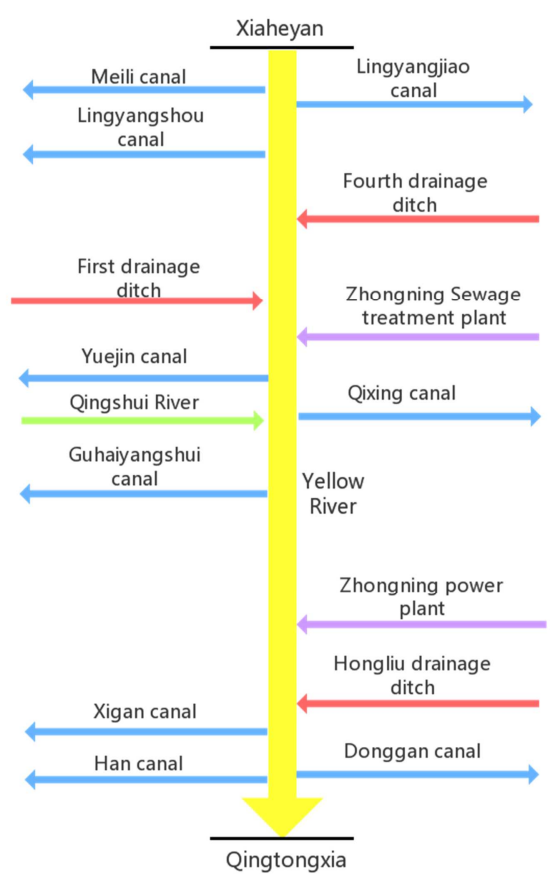

Figure 5. Conceptual sketch map of Xia-Qing section.

2). As is shown in figure 7 , the basin above Xiaheyan section and Qingtongxia section mainly is non-point source pollution. But the basin above Shizuishan section mainly is point source pollution. This is because before the Qingtongxia section on both sides of the Yellow River, the quantity of factories and enterprises and drainage ditch is few. After rainfall, the $\mathrm{NH}_{3}-\mathrm{N}$ pollution is into the Yellow River through surface runoff、 farm drainage and underground leakage, what is non-point source pollution. But before the Shizuishan 
section on both sides of the Yellow River, there is a large number of factories and enterprises, living area, drainage ditch, what leads to the basin above Shizuishan section is mainly the point source pollution.

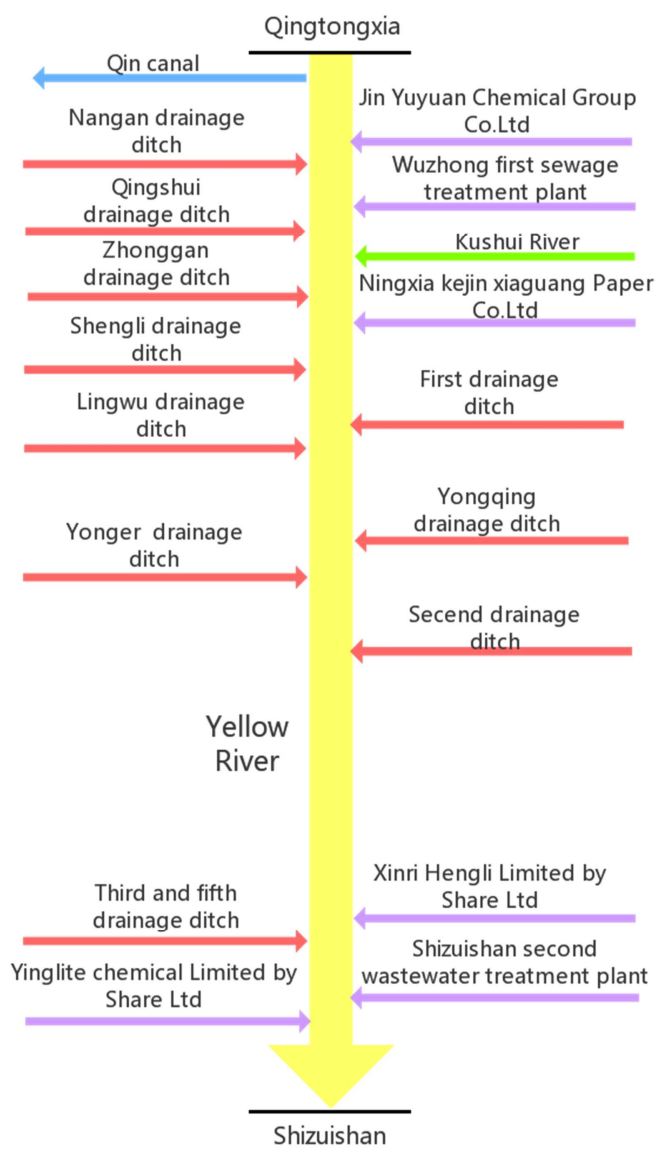

Figure 6. Conceptual sketch map of Qing-Shi section.

\subsection{The Temporal Characteristics of NH3-N Pollution}

1). As is shown in figure 8 , the $\mathrm{NH}_{3}-\mathrm{N}$ pollution load value of Xiaheyan section and Qingtongxia section shows the following temporal rule: wet period $>$ flat period $>$ drought period.

Because rainfall increases in wet season, so the amount of water in the Yellow River increase and the pollutants are diluted. However, with the increase of rainfall, it will lead to a large number of nitrogen pesticides enter the Yellow River through surface runoff, drainage and underground drainage and other ways. These pesticides are from the both sides land of the Yellow River. And through the actual investigation, we find that the drainage ditches before the two sections have more sewage. At the same time, the concentration of sewage is far greater than falt period and drought period. So it leads to the rule of above.

2). The $\mathrm{NH}_{3}-\mathrm{N}$ pollution load value of Shizuishan section shows the following temporal rule:drought period $>$ flat period $>$ wet period.

Based on the known data, the monthly emissions of $\mathrm{NH}_{3}-\mathrm{N}$ pollution load of factory enterprise and drainage ditch is basically the same. Because rainfall increases in wet season, so the amount of water in the Yellow River increase and the pollutants are diluted. So the $\mathrm{NH}_{3}-\mathrm{N}$ pollution load in wet period is the lowest in the three periods. And the $\mathrm{NH}_{3}-\mathrm{N}$ pollution load in drought period is the highest in the three periods.

3). Even though the $\mathrm{NH}_{3}-\mathrm{N}$ pollution load value of Shizuishan section in wet period is the lowest in the three periods, it is still higher than the $\mathrm{NH}_{3}-\mathrm{N}$ pollution load of Xiaheyan section and Qingtongxia section in wet period.

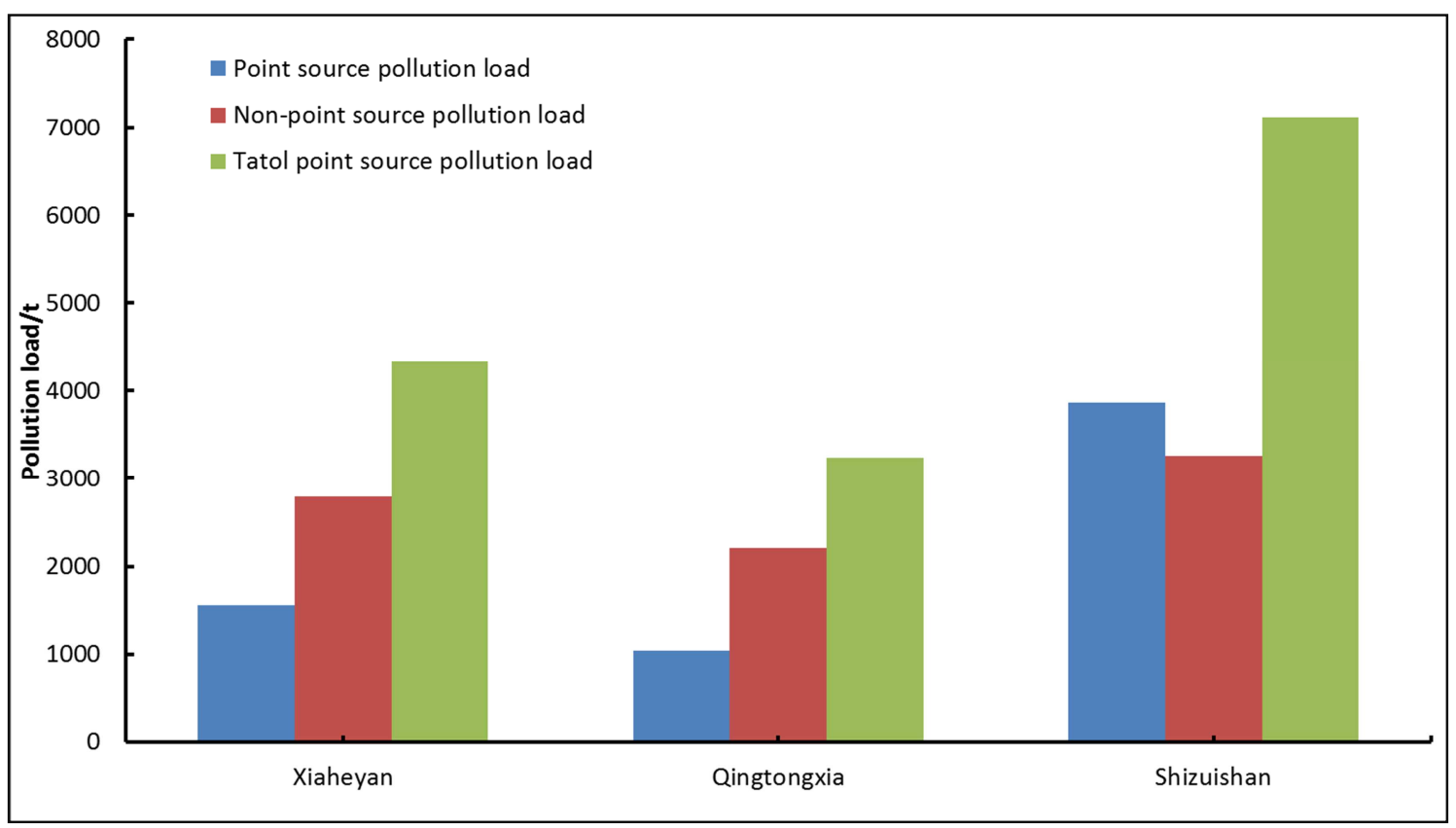

Figure 7. Sketch map of $\mathrm{NH}_{3}-\mathrm{N}$ pollution load. 


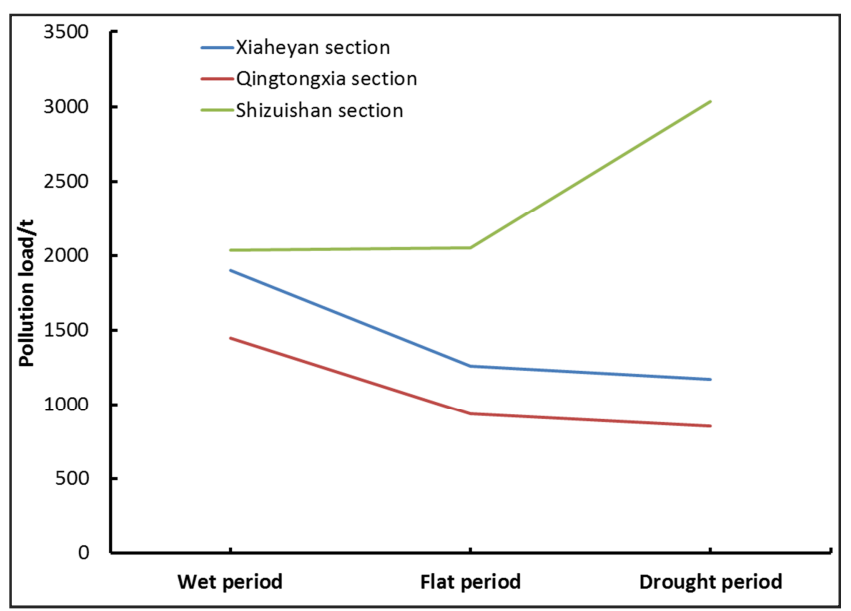

Figure 7. Sketch map of $\mathrm{NH}_{3}-\mathrm{N}$ pollution load.

\section{Conclusion and Suggestion}

1). The basin before Xiaheyan section and Qingtongxia section is mainly non-point source pollution. And non-point source pollution load accounts respectively for $64.37 \%$ and $68.05 \%$ of the total pollution load. The main reason is the $\mathrm{NH}_{3}-\mathrm{N}$ pollution in the farmland enters the Yellow River through the surface runoff, farmland drainage and underground leakage, etc. So we can improve the pollution of the Yellow River from the perspective of agriculture. For example, we can reduce fertilizer loss by improving fertilization methods; strengthen planting trees and grass, forest, etc [10].

2). The basin before Shizuishan section is mainly point source pollution. And point source pollution load accounts for $54.28 \%$ of the total pollution load. The main reason is that there is a large number of factories, enterprises, drainage ditches and residential areas in the both sides land of the Yellow River. We propose to develop the relevant laws and supervision system to reduce the discharge of pollutants of the factories and enterprises.

3). Promoting the construction of talents. Strengthening the training of professional staff. Improving the quality of professional technology. Making regular organization to carry out learning exchanges, improving the level of professional team.

4). Promoting public participation in water environment protection. Adhering to the people-oriented, improving the level of public participation, and thus improving the region's water environment protection and water level.

\section{Acknowledgements}

This thesis is supported by the fund project: The response mechanism and reasonable development and utilization of groundwater in Yinchuan plain. And my tutor, Professor Qian hui, and my friend, Feng Jing, have given me academic help. Thank you sincerely!

\section{References}

[1] RUAN Xiaohong, SONG Shixia, ZHANG Ying, "Research progress and application of non point source pollution model", J. YELLOW RIVER, Vol. 24, No. 11, pp: 25-26, Nov. 2002.

[2] YANG Yuhong, SHEN Wanbin. "Preliminary Study on Estimating Surface Water Non Point Source Pollution Loads", J. Journal of Jilin University (Earth Science Edition), Vol. 36 Sup., pp: 105-106, Nov. 2006.

[3] LIU Zhuang, CHAO Jianying, ZHANG Li, XIE Yufeng, ZHUANG Wei, HE Fei, "Current status and problems of non-point source pollution load calculation in China", J. ADVANCES IN WATER SCIENCE, Vol. 26, No. 3, pp: 432-433, May. 2005.

[4] Johns P J. "Evaluation and management of the impact of land use change on the nitrogen and phosphorus load delivered to surface waters: the export coefficient modeling approach", J. J of Hydrology, Vol. 183, No. 3, pp: 323-349, 1996.

[5] CAI Ming, LI Huaien, ZHANG Yongtao. "Rainfall deduction method for estimating non-point source pollution load for watershed", J. Jour. of Northwest Sci-Tech Univ. of Agri. and For. (Nat. Sci. Ed.), Vol. 33, No. 4, pp:2102-106, April. 2005.

[6] CAI Ming. "Nitrogen pollution and its control planning in Shaanxi reach of Weihe River", D. Xi'an: Xi'an University of Technology, 2004.

[7] HONG Xiaokang, LI Huaien. "Correlation Method of Water Quality and Quantity and Its Application to Load Estimation of Nonpoint Source Pollution", J. Journal of Xi' an University of Technology, Vol. 16, No. 4, pp: 384-386, 2000.

[8] ZHU Lei, LI Huaien, LI Jiake, "Estimation of Pollution Load above Linjiacun Section in the Weihe River Watershed Based on Characteristic Load Method", J. Journal of Xi'an University of Technology, Vol. 28, No. 2, pp: 152-156, 2012.

[9] Ren Xuerong, Zhou Huaidong, Li Weidong, "Analysis of ammonia- nitrogen pollution in Ningxia section of the Yellow River", J. CHINA WATER RESOURCES, pp: 40-41, May. 2005.

[10] XIE Tao, KANG Caixia, TANG Wenkui, ZHANG Xinying, "Status and Control Measures of Agricultural Non-point Pollution", J. Journal of Guangxi Teachers Education University: Natural Science Edition, Vol. 27, No. 4, pp: 71-72, Dec. 2010. 